\title{
Healthcare Professionals as Gatekeepers in Research Involving Refugee Survivors of Sexual Torture - an Examination of the Ethical Issues
}

Roghieh Dehghan Zaklaki* (corresponding author) and James Wilson**.

Developing World Bioethics, 2019, doi: 10.1111/dewb.12222

* Honorary Clinical Research Associate, Gender Centre, Institute for Global Health, Faculty of Population Health Sciences, University College London, 30 Guilford Street, London.

r.zaklaki@ucl.ac.uk

** Associate Professor, Department of Philosophy, UCL, Gower Street, London WC1E 6BT

\begin{abstract}
This paper examines the ethical issues that arise when healthcare providers act as gatekeepers to research involving vulnerable populations. Traumatised refugees serve as an example of this subset of research participants. Highlighting the particular vulnerabilities of this group, we argue that specific ethical considerations are required that go beyond the conventional research approaches. While gatekeeping responds to some of those vulnerabilities, it risks wronging through unwarranted paternalism. Instead, we will propose that relational ethics of justice and care serves as a more appropriate framework for responding to the challenges of research involving traumatised refugees. Specifically, such a framework allows us to reflect more deeply on the role of the gatekeeper. In conclusion, we recommend that clinicians and researchers collaborate with survivors' advisory groups in the development of specific research ethical guidelines.
\end{abstract}

Keywords : Research ethics, gatekeeping, refugees, trauma, torture 


\section{Introduction}

In January 2017, one of the authors of this paper obtained the approval of a university research ethics committee to undertake a study on the mental health impacts of sexual torture in a cohort of refugee torture survivors from Muslim-majority countries in the UK. However, notwithstanding the fact that the university's ethical approval was in place, healthcare providers denied access to the torture victims. ${ }^{1}$ While part of the reason seemed to be related to their high workload, the main barrier was concerns for the vulnerability of the target population. Since this experience has important resonance internationally too, this essay will critically examine the ethical issues implicated in gatekeeping research participation of vulnerable population by taking tortured refugees as a 'case study'- with a special focus on sexual violence. We will argue that the wellmeaning paternalism of healthcare providers in this context and similar circumstances fails to provide an ethically appropriate response. While research on torture in general has been proliferating since the 1980s, sexual torture has received almost no attention. This academic silence is partly-if not mostly-due to ethical concerns of harm to research participants. ${ }^{2,3,4}$ Accordingly, when studying sexual violence in refugee torture survivors, clinicians and human rights activists cite their ethical duty of protection to restrict access to survivor-research participants. Within this context, we will argue that healthcare professionals' gatekeeping of research participation can best be assessed within the relational ethics of justice and care. The paper divides into four parts, which together challenge the common understanding of what constitutes vulnerability in this cohort, as well as the traditional ethical responses to those vulnerabilities. It begins with a brief background on research bioethics and gatekeeping. The second section evaluates the vulnerabilities of refugee torture survivors, opposing the commonly held view that tortured refugees are vulnerable particularly due to the risk of retraumatisation, rather than because of other variables of vulnerability, such as socio-political disadvantages.

Section three discusses the role of paternalism as the usual response to vulnerability. Drawing on principle-based frameworks that often regulate the relationship between the researcher and the human research subject, we argue that while these approaches are somewhat relevant, they fail to capture the complexity and plurality of the ethics of researching refugee torture survivors. We pursue two main lines of argument to illustrate this point; the first argument centres on the particular vulnerabilities of torture survivors that require specific ethical considerations, and the second argument relates to the issues of care, power, and responsibility as they pertain to the role of gatekeepers. ${ }^{5}$ We acknowledge that tortured refugees do and should expect some degree of gatekeeping from professionals as a form of protection, but we argue that such gatekeeping should

1 NHS ethical approval was not required since the research did not involve NHS institutions/patients.

2 Agger, I. (1989). Sexual torture of political prisoners: An overview. Journal of Traumatic Stress 2(3), pp. 305-318.

3 Cunningham, M. \& Cunningham, J.D. (1997). Patterns of Symptomatology and Patterns of Torture and Trauma Experiences in Resettled Refugees. Australian \& New ZealandJournal of Psychiatry 31(4), pp. 555-565.

4 Canning, V. (2016). Unsilencing Sexual Torture: Responses to Refugees and Asylum Seekers in Denmark. British Journal of Criminology 56(3), pp. 438-455.

5 Davis, J.C. (2003) Gate Keeping in Family Therapy Supervision: An Exploratory Qualitative Study. Purdue University Library. Retrieved January 5, 2018, from http://docs.lib.purdue.edu/dissertations/AAI3124139/ 
occur within the relational ethics of justice and care. Thus, the final section argues that gatekeeping should take the form of a self-reflexive dialogue between all stakeholders: the researcher, the professional caregiver and the torture survivor. Moreover, healthcare professionals who attend traumatised refugees ought to support research that encompasses this cohort's voice and respects their interpretation of autonomy and beneficence. Such an approach is crucial given the strong evidence of refugees' unmet health needs, especially psychological difficulties. ${ }^{6,7}$ Engaging with academic researchers to co-create an institutional environment that will support inclusion of traumatised refugees as research participants is part of the ethical and professional duties of healthcare professionals who have the privilege of working with this hard-to-reach population.

\section{Background}

There is no doubt that the 21.3 million refugees worldwide have complex physical and psychological health needs. A review of literature bearing on the issue of mental health in UK refugees indicates a higher prevalence of mental disorders and somatisation as well as a poor response to conventional therapeutic approaches..$^{8,9,10,11}$ Similar outcomes can also be found in torture survivors, especially those subjected to sexual torture. ${ }^{12,13,14,15}$ The 1984 Convention Against Torture defines torture as mental and physical suffering inflicted or sanctioned by official authorities. Likewise, sexual torture is any sexual offence committed within this context. ${ }^{16}$ In high

6 Bhugra, D., \& Becker, M.A. (2015). Migration, cultural bereavement and cultural identity. World Psychiatry 4(1), pp. 18-24.

7 Watts, C., Hossain, M., \& Zimmerman, C. (2013). War and Sexual Violence- Mental Health Care for Survivors. The New England Journal of Medicine 368(23).

8 Craig, T., Mac, Jajua. P., \& Warfa, N. (2009). Mental health care needs of refugees. Psychiatry $8(9)$

9 McColl, H., \& Johnson, S. (2006). Characteristics and needs of asylum seekers and refugees in contact with London community mental health teams. Social Psychiatry and Psychiatric Epidemiology 41, pp. 789-795

10 Karpuk, D., Cunningham, M., Kaur, R., Short, S., Cannon, C., Odunukwe, D., \& Beech, J. (2012). Understanding how asylum seekers and refugees access and experience mental health support in Leeds. A Report on PAFRAS/Touchstone Action Research Project 2011-2012, NHS Airedale, Bradford and Leeds.

11 Watters, C. (2011). Emerging paradigms in the mental health care of refugees. Social Science \& Medicine 52, pp. 1709-1718.

12 Kira, I.A., Smith, I., Lewandowski, L., \& Templin, T. (2010). The Effects of Gender Discrimination on Refugee Torture Survivors: A Cross-Cultural Traumatology Perspective. Journal of the American Psychiatric Nurses Association 16(5), pp. 299-306.

13 Oosterhoff, P., Zwanikken, P., \& Kett, E. (2004). Sexual torture of men in Croatia and other conflict situations: An open secret. Reproductive Health Matters 12(23), 68-77

14 Peel, M. (2004). Rape as a method of torture. London: Medical Foundation for the Care of Victims of Torture

15 Seltzer, A. (2004). Rape and mental Health: the Psychiatric Sequelae of Violation as an Abuse of Human Rights. In: M. Peel (Ed), Rape as a Method of Torture. London: Medical Foundation for the Care of Victims of Torture

16 Convention against Torture and Other Cruel, Inhuman or Degrading Treatment or Punishment. United Nations General Assembly, December 1984. Retrieved Nov 28, 2016, from http://www.un.org/documents/ga/res/39/a39r046.htm 
income countries, torture is reported by $30 \%$ to $84 \%$ of asylum seekers. Amongst those who report being tortured, $78 \%-80 \%$ of women and $25 \%-56 \%$ of men have also experienced sexual torture. The wide variations in these estimates reflect methodologically diverse investigations and heterogeneity of study populations. ${ }^{17,18,19}$

It is becoming increasingly evident that the long-term impacts of violence are linked to a victim's socio-cultural background, and the most effective rehabilitation services are contextualised to an individual's specific history ${ }^{20,21,22,23}$. Hence, in the first Global Summit to End Sexual Violence that took place in London in 2014, the 148 participating countries endorsed a resolution that supported the promotion and funding of further research. ${ }^{24}$ Despite its high prevalence and poor health outcomes, sexual torture has received little attention in the world of health-related research. This modicum of academic interest seems to be principally driven by ethical issues surrounding research involving sexually traumatised refugees. ${ }^{25,26}$ Ethical concerns for study participants are frequently framed within a principlist approach. ${ }^{27}$ Principlism analyses ethical decisions by relying on the four principles of autonomy, non-maleficence, beneficence and justice. As such, a research project is deemed ethical when autonomy is established through informed consent and voluntary participation, the study's benefits outweigh its harms, confidentiality is respected, and justice is secured by a fair distribution of the advantages and disadvantages of the research. ${ }^{28,29}$ The principles are in place to protect research participants from an approach that would allow the interest of individuals to be sacrificed for the wider social benefit. This bioethical framework plays a major role in establishing the perspectives and the norms that inform decisions of both Research

17 Busch, J., Hansen, S.H., \& Hougen, H.P. (2014.) Geographical distribution of torture: An epidemiological study of torture reported by asylum applicants examined at the Department of Forensic Medicine. University of Copenhagen. Torture 25(2).

18 Kalt, A., Hossain, M., Kiss, L., Zimmerman, C. (2013). Asylum Seekers, Violence and Health: A Systematic Review of Research in High-Income Host Countries. American Journal of Public Health. 103(3), pp. 30-42.

19 Lunde, I., \& Ortmann, J. (1990). Prevalence and sequelae of sexual torture. The Lancet. 336 (8710), pp. 289-291

20 Bracken, P. (2001). Post-modernity and post-traumatic stress disorder. Social Science \& Medicine 53(6), pp. 733-743

21 Leatherman, J. L. (2011). Sexual Violence and Armed Conflict. Cambridge: Polity Press

22 Summerfield D (1996) The Impact of War and Atrocity on Civilian Populations: Basic Principles for NGO Interventions and a Critique of Psychosocial Trauma Projects. Retrieved August 26, 2018, from https://www.freedomfromtorture.org/sites/default/files/documents/SummerfieldImpactOfWar\%20.pdf

23 Watts, Hossain \& Zimmerman, op. cit. note 7

24 See: https://www.gov.uk/government/collections/2014-global-summit-to-end-sexual-violence-inconflict

25 Canning, op. cit. note 4

26 Seltzer, op. cit. note 15

27 Beauchamp, T., \& Childress, J. (2013). Principles of Biomedical Ethics. New York: Oxford UniversityPress

28 Dominelli, L., \& Holloway, M. (2008). Ethics and governance in social work research in the UK. British Journal of Social Work 38(5), pp. 1009-102.

29 Fisher, C. B. (1999). Paper Three: Relational Ethics and Research with Vulnerable Populations. In: Research Involving Persons with Mental Disorders That May Affect Decision making Capacity, Report, National Bioethics Advisory Commission, US, March. Retrieved August 26, 2018 from https://bioethicsarchive.georgetown.edu/nbac/capacity/volumeii.pdf 
Ethics Committees (RECs) and healthcare providers who gatekeep access to research participants of sexual violence. ${ }^{30,31}$ Gatekeeping, a word rooted in military tradition, describes 'the activity of controlling, and usually limiting, general access to something', ${ }^{32}$ Within the realm of health research, the word denotes 'the process whereby healthcare providers prevent access to eligible patients for research recruitment'. ${ }^{33}$ After obtaining ethical approval from academic institutions, gatekeeping in the context of tortured refugees research occurs by various actors: healthcare professionals (HCPs), human rights activists and community leaders. While the dilemma remains old - 'harm avoidance, the risks to the individual versus the benefits to the community, and respect for persons' ${ }^{34}$, changing socio-political contexts may require a re-appraisal of old principles. Some scholars, like Mackenzie et $\mathrm{al}^{35}$, raise important questions about whether biomedically orientated RECs are competent enough to decide the ethical issues of refugee and social science research. If they are not, then the role of the gatekeeper could be seen as especially important backstop. Conversely, gatekeeping has been strongly challenged by researchers in palliative care, a relatively new field of medicine in need of methodologically robust studies. Palliative care studies are routinely hampered by recruitment issues, resulting in research with small sample sizes or, more often, research prospects that never come to fruition. For that reason, Kars et $\mathrm{al}^{36}$ undertook a systematic review to examine the reasons for gatekeeping in palliative care research; they found that concerns of patient vulnerability and the subsequent protective approach of healthcare professionals were the most frequently encountered barriers to participant recruitment. As a result, it is not uncommon for palliative care researchers to acknowledge that the 'efforts made with recruitment' outweigh 'the outcome' they achieve ${ }^{37}$, and this also parallels one of the authors' own experience of conducting an investigation into the mental health impacts of sexual torture in refugees. Crucial to gaining a more perspicuous overview of the ethics of gatekeeping for this cohort is a better understanding of their vulnerabilities, as the next section examines.

\section{Vulnerability}

The term vulnerability will be used here to refer to individuals and groups who are relatively more fragile than the general population due to certain characteristics that interfere with human thriving

30 Fraga, S. (2016). Methodological and ethical Challenges in Violence Research. Porto Biomedical Journal 1 (2), pp. 77-80.

31 Mackenzie, C., McDowell, C., \& Pittaway, E. (2007). Beyond "do no harm": The challenge of constructing ethical relationships in refugee research. Journal of Refugee Studies 20 (2), 299-319

32 Willems, D. L. (2001). Balancing rationalities: Gatekeeping in health care. Journal of Medical Ethics, 27 (1),pp. 25-29.

33 Sharkey, K., Savulescu J, Aranda, S., \& Schofield, P. (2010). Clinician gatekeeping in clinical research is not ethically defensible: an analysis. Journal of Medical Ethics 36(6), pp. 363-366.

34 McWhirter, R.E. (2012). The history of bioethics: implications for current debates in health research. Perspect Biol Med 55 (3), pp. 329-338.

35 Mackenzie, McDowell, \& Pittaway, op. cit. note 31

36 Kars, M. C., Van Thiel, J.G., Van der Graaf, R., Moors, M., \& De Graeff, A. (2015) A systematic review of reasons for gatekeeping in palliative care research. Palliative Medicine 30(6), pp. 533548.

37 Ewing, G., Rogers, M., Barclay, S., McCabe, J., Martin, A, \& Todd, Ch. (2004). Recruiting patients into a primary care based study of palliative care: why is it so difficult? Palliative Medicine $18,452-456$ 
and prospering. ${ }^{38}$ Vulnerability is a complex and socially constructed concept that is mediated by a whole set of variables, including 'race/ethnicity, socioeconomic status, geography, gender, age, disability status, and risk status related to sexual identity and behaviour' ${ }^{39}$ Similarly, the vulnerabilities of refugee survivors of sexual torture is plural and compounded; its dynamics are amplified by cultural differences and the historic power imbalances enmeshed with abuse and subordination. ${ }^{40}$ Three of these vulnerabilities transpire as central to research ethics that concern refugees exposed to sexual torture: first, the history of trauma coupled with the sensitivity of sexual violence as a research topic; second, belonging to a minority group in the host country; third, the political dimension of torture which leads to mistrust in figures of authorities and official power.

\section{Trauma: the fear of re-traumatisation}

There are divergent opinions on the propriety of sexual torture as a topic for health research. On one end of the spectrum, investigators like Canning (2016) ${ }^{41}$ advocate for the 'unsilencing' of sexual torture; at the other end, the World Health Organisation (WHO) has argued that the silence around sexual violence is inevitable and 'well-founded' because of its potential to cause 'social, physical, psychological and/or legal' harm. ${ }^{42}$

More specifically, sexual torture is a type of trauma that is routinely linked to post-traumatic stress disorder (PTSD); ${ }^{43,44}$ hence, re-traumatisation of study participants is thought by many to be highly likely. However, these intuitively sound concerns have not been verified by empirical papers produced to date. In fact, the risk of re-traumatisation is mostly refuted by the current body of literature investigating sexual violence in the general population (not tortured or conflict

38 Wiles, J. (2011). Reflections on being a recipient of care: vexing the concept of vulnerability. Social \& Cultural Geography 12 (6), pp. 573-588.

39 Rogers, J., \& Kelly, U. A. (2011). Feminist intersectionality: bringing social justice to health disparities research. Nurs Ethics 18 (3), pp. 397-407.

$40 \quad$ Mackenzie, McDowell, \& Pittaway, op. cit. note 31

41 Canning, op. cit. note 4

42 World Health Organization (2007). WHO ethical and safety recommendations for researching, documenting and monitoring sexual violence in emergencies. Retrieved August 26, 2018, from http://www.who.int/gender/documents/OMS_Ethics\&Safety10Aug07.pdf

43 Basoglu, M., Jaranson, J.M, Mollica, R., \& Kastrup M (2001). Torture and Mental Health. In: E. Gerrity, F. Tuma, \& TM. Keane (Eds), The Mental Health Consequences of Torture (pp.35-62). New York: Springer US.

44 Agger, I., \& Jensen S.B. (1993). The Psychosexual Trauma of Torture. In J.P. Wilson, \& B. Raphael (Eds.), International Handbook of Traumatic Stress Syndromes (pp. 685-702). New York: Springer US. 
zones). ${ }^{45,46,47,48,49,50}$ For example, a meta-analysis of 70 samples investigating participants' reaction to trauma research ${ }^{51}$ reveals that while some factors such as trauma-exposure, the severity of trauma, sexual violence and PTSD are linked with adverse psychological impact in trauma research, the resulting distress is minimal and short-lasting. Equally important, the majority of research participants found the experience to be beneficial and empowering. On closer inspection, however, these outcomes are open to a number of critiques. For instance, at the methodological level, there is limited diversity of samples, inconsistent heterogeneity of trauma types (from childhood sexual trauma to adult rape and from college students to psychiatric inpatients) and varying trauma definitions used in the studies. What's more, the stated outcomes might not be transferable to the refugee population. It is also important not to fully dismiss the concerns of healthcare providers since their concerns are informed by their own experiences of working with this population group. They recognise the possibility that recalling the trauma history can cause acute physical symptoms, panic attacks and hyperventilation, potentially requiring referral to Accident and Emergency services. Still, their experiences often reflect the dynamics of either a clinical setting or an interview for medicolegal report-writing rather than a research context. Subsequently, there may be an inherent tension between the clinical and research perspectives.

In summary, the assessment of sexual torture as a topic too sensitive and too risky for research remains no more than speculation at the moment due to lack of evidence. The discrepancy between the ethical presumption of intolerable risk to participants and the empirical data necessitates a thorough normative and theoretical analysis of the ethical issues surrounding research on sexually traumatised refugees. The following discussions will proceed in this light.

\section{Minority research}

'Instability, insecurity, fear, dependence and loss of autonomy' as well as the 'disruption of community and family support systems', ${ }^{52}$ linguistic challenges and racism comprise some of the

45 Decker, S. E., Naugle, A.E., Carter-Visscher, R., Bell, K., \& Seifert, A. (2011). Ethical Issues in Research on Sensitive Topics: Participants' Experiences of Distress and Benefit. Journal of Empirical Research on Human Research Ethics 6(3), 55-64.

46 Goossens, I., Nicholls, T.L., Torchalla, I., Brink, J., \& De Ruiter, C. (2016). The Perceived Impact of Trauma-Focused Research on Forensic Psychiatric Patients with Lifetime Victimization Histories. Journal of Empirical Research on Human Research Ethics 11(4), pp. 334-345.

47 Jain, S., Nazarian, D., Weitaluf, J.C., \& Lindley, S. (2011). Overview of bioethical issues in contemporary ptsd treatment and research: Considering priorities for future empirical ethics investigation. AJOB Primary Research 2(4), pp. 26-32.

48 Johnson, M. E., Kindo, K.K., Brems, Ch., Ironside, E.F., \& Eldridge, G.D. (2016). Mental Health Research in Correctional Settings: Perceptions of Risk and Vulnerabilities. Ethics and Behavior 26(3), pp. 238-251.

49 Legerski, J. P., \& Bunnell,S. L. (2010). The risks, benefits, and ethics of trauma-focused research participation. Ethics and Behavior 20(6), pp. 429-442.

50 Nielsen, L. H, Hansen M, Elklit, A., \& Bramsen, R.H. (2016.) Sexual Assault Victims Participating in Research: Causing Harm When Trying to Help? Archives of Psychiatric Nursing 30 (3), pp. 412 417.

51 Jaffe, A. E., DiLillo, D., Hoffman, L., Haikalis, M., \& Dykstra, R.E. (2015). Does it hurt to ask? A meta-analysis of participant reactions to trauma research. Clinical Psychology Review 40, pp. 4056

52 WHO, op, cit. note 42 
unique burdens for displaced and traumatised individuals. These vulnerabilities raise a series of ethical issues which Research Ethics Committees (RECs) often respond to by safeguarding autonomy and voluntary participation through informed consent as the main regulatory tools. While high quality informed consent is clearly crucial for research involving tortured refugees, the commonly made assumption that informed consent is a uniquely effective means of respecting autonomy is questionable in vulnerable populations. ${ }^{53}$ For example, vulnerable research participants may not be able to distinguish between therapeutic and experimental interventions, thereby undermining any consent provided. ${ }^{54}$ Individuals might also be misled by the wording and phrases used to describe a project. Further, there is a risk that this population could fall under the false impression that research carries a direct benefit to them or that participation is a legal requirement. The latter point in particular deserves special emphasis; refugees or asylum seekers with an uncertain legal status can find themselves in situations that curtail their sociopolitical powers, adding to the risk of coercion or acquiescence with authority of the researcher and healthcare providers. Additional risks of coercion can result from incentives or healthcare professionals' involvement in recruitment. ${ }^{55}$ The latter becomes an issue when one turns to HCPs for access to participants. For instance, asylum seekers may assume that research participation may positively impact their legal status or garner the support or HCPs. This is certainly not to say that informed consent is redundant; rather, great care needs to be taken in obtaining consent, and consent alone is insufficient to establish that a research protocol is ethical. In addition, group stigmatization is regarded as one of the undeniable risks of minority research because it involves a group of people who may already be subjected to hostility and stereotypes within a host country. A study that is not handled with care can potentially compound their discrimination and oppression. Consider the study that we discussed in the introduction, which seeks to investigate the impact of sexual torture on Muslim refugees. Given the anguish and humiliations Muslim men suffered in Abu Ghraib and Iraqi prisons at the hands of coalition authorities who leveraged stereotypes of sexualised and racialised Muslim men, such a line of study may be construed as reinforcing the same stigmas that were operationalised by torturers in order to demean and degrade Muslim men. ${ }^{56}$ Acknowledging that 'race-based research can and has been used to justify segregation, political subordination, and hostile and demeaning stereotypes', ${ }^{57}$ we concur with those scholars who proclaim that in working with disadvantaged groups, the principle of non-maleficence, while essential, is not enough to address the multilayered vulnerabilities of human research subjects Mackenzie, McDowell and Pittaway, 2007; Pittaway, Hugman and Bartolomei, 2010). ${ }^{58,59}$

53 O'Neill, O. (2003). Some limits of informed consent. Journal of medical ethics 29(1), pp.4-7.

54 Sugarman, J., Kass, N.E., Goodman, S.N., Perentesis, P., Fernandes, P., \& Faden, R.R. (1998). What patients say about Medical research? Ethics \& Human Research. The Hastings Center report 20 (4), pp. 1-7

55 Mackenzie, McDowell, \& Pittaway, op. cit. note 31

56 Razack, S., \& Razack, S.H. (2005). How Is White Supremacy Embodied? Sexualized Racial Violence at Abu Ghraib. Canadian Journal of Women and the Law 17(2), pp. 341-363.

57 Fisher, op, cit. note 42, p.13

58 Hugman, R., Pittaway, E., \& Bartolomei, L. (2011). When "do no harm" is not enough: The ethics of research with refugees and other vulnerable groups. British Journal of Social Work 41(February), pp. 1271-1287.

59 Pittaway, E., Hugman, R. \& Bartolomei, L. (2010). Stop Stealing Our Stories”: The ethics of research with vulnerable groups. Journal of Human Rights Practice 2(2), pp. 229-251. 


\section{Mistrust in authorities}

Torture, by definition, is a trauma inflicted by or on behalf of authorities. ${ }^{60}$ This renders it distinct from other forms of traumatic events such as car accidents, natural disasters or intimate partner violence. Abuse at the hands of authorities creates a general mistrust in those with power, including healthcare professionals. It seems that this association between power and experiences of abuse represents another level of vulnerability for this cohort ${ }^{61}$ - a vulnerability that is closely linked to trust. Trust involves making oneself vulnerable. As Dumouchel puts it, 'To trust is to act in such a way to give another agent power over us ${ }^{\prime 62}$. Trust is the bone and marrow of clinical work because of the power imbalance and vulnerability of the patients. Likewise, some experts assert that for potential human research subject, trust is more imperative than informed consent. Trust seems to stem from a sense of confidence in a study being conducive to the patients' best interests and not bringing harm on participants. ${ }^{63,64,65}$

While a trusting relationship is fundamental in all fields of medicine, it bears particular importance in the work of healthcare providers and their tortured patients. The fragility of this relationship lies in the risk of evoking a sense of helplessness in the patient and replicating a power dynamic associated with torture. What is more, any form of interview, be it for clinical or academic purposes, may invoke the memory of Home Office interviews for asylum seekers. Home Office interviews are often described as 'interrogations' and 'traumatising' by survivors. For instance, in the ongoing UK study with torture survivors that one of the authors initiated, many potential participants needed reassurance that the study was not associated with the Home Office.

Consequently, failing to put certain measures in place to safeguard patients against a potentially harmful study compromises the relationship between the healthcare provider and the tortured victim, ultimately jeopardising their treatment and health as well as the trust within the wider community of tortured refugees. As an example of this protectiveness in action, in the aforementioned project, a number of healthcare providers refused to display recruitment flyers for research participants in their buildings. It is plausible that these providers were concerned that doing so would have been seen as demonstrating a level of support for a study that they viewed as carrying too many risks for their patients. If the research distressed the participants, then it is likely that the treating clinician would be thought to have failed to protect and act in the best interest of her patient.

60 Convention against Torture and Other Cruel, Inhuman or Degrading Treatment or Punishment. United

Nations General Assembly, December 1984. Retrieved 25 September 2018 from http://www.un.org/documents/ga/res/39/a39r046.htm

61 Mackenzie, McDowell, \& Pittaway, op. cit. note 31

62 Dumouchel, P. (2005). Trust as an Action. European Journal of Sociology 46(3), pp. 417-428

63 Kass, N.E, Sugarman, J., Faden, R., \& Schoch-Spana, M. (1996). Trust, The fragile foundation of contemporary biomedical research. The Hastings Center report, 26(5), pp. 25-29

64 McDonald, M., Townsend, A., Cox, S.M., Paterson, N.D., \& Lafreniere, D. (2008) Trust in health research relationships: accounts of human subjects. Journal of empirical research on human research ethics 3(4), pp. 35-47

65 Resnik, D.B. (2011). Scientific Research and the Public Trust. Science and Engineering Ethics, 17 (3), pp. 399-409 
Such gatekeeping is nearly always a good faith attempt to respond to specific risks in crosscultural research of vulnerable groups that are believed to be insufficiently addressed by bioethical codes. Yet, while gatekeepers have the intention to protect, they are also acting paternalistically in a way that requires further scrutiny.

\section{Paternalism}

Paternalism can be defined as intervening to advance an individual's interests, but without their consent. ${ }^{66}$ Paternalism can be divided into two general categories, soft and hard. In soft paternalism, agents are safeguarded against non-autonomous acts (such as harming themselves when under the influence of drugs), but hard paternalism prevents acts that are informed and voluntary. Let us suppose that a research study provides correct and thorough information to a potential participant, consent is informed and voluntarily given, and the torture survivor is not suffering from an acute psychiatric illness that renders him incompetent. The gatekeeper is also aware of these facts. In this case, gatekeeping will clearly be hard paternalism. What if, any, aspects of the torture survivor's vulnerability would permit such gatekeeping?

On the one hand, gatekeeping could be defended on the basis of the duties associated with a doctor-patient relationship which presuppose protection and care - a type of implicit request from the patient. On the other hand, one could also argue that gatekeeping protects the community of torture survivors against group stigmatisation, even if it is not a concern of the individual. However, such a presumption becomes problematic since individuals and communities do not have the chance to voice a preference and would have no knowledge that a research opportunity even exists. As such, a level of protection that requires complete silence about even the existence of a research project seems problematic to endorse. As Freedman ${ }^{67}$ states: 'It is a terrible thing to be hated or persecuted; it is far worse to be ignored, to be notified that 'you don't count" ${ }^{68}$ In addition, it can be argued that healthcare professionals tend to underestimate patients' resilience, causing their assessment of a participant's vulnerability to be inconsistent with the individual's self-perception. Some palliative care researchers, for example, worry that 'protective power' may become 'oppressive' when it 'restict(s) rather than safeguard(s) opportunities to improved services' ${ }^{69}$ When hard paternalism is justified, it is usually thought to be in cases where the intervention enforced is clearly better for the paternalised person than allowing them to make their own choice. However, in this case it is far from clear that denying the tortured refugees the option to take part in research would be better for those denied access; in fact it may be worse them to be further disempowered, after having already been silenced and marginalised.

The case for soft paternalism in this context is somewhat more plausible, but still ultimately problematic. In order to approve the research project as a whole, the REC must be persuaded that the benefits are proportionate to the expected risks for the participants, and that these risks have been minimised. The REC will also have satisfied itself of the appropriateness of the information to

66 Dworkin, G. (2017). Paternalism. In: E.N. Zalta (Ed), The Stanford Encyclopedia of Philosophy. Retrieved January, 7, 2018 from https://plato.stanford.edu/archives/win2017/entries/paternalism/

67 Freedman, B. (1975). A moral theory of informed consent. Hastings Centre Report 5(4), pp. 32-39

68 Ibid: 32

69 Witham, G., Beddow, A., \& Haigh, C. (2015). Reflections on access: too vulnerable to research? Journal of Research in Nursing 20(1), pp. 28-37 
be provided to research participants, and the consent process. This informed consent process will oblige the researcher to provide the participant with adequate information about the study and ensure that she is competent enough to comprehend it, weighing the risks versus the benefits in order to arrive at a voluntary decision.

Healthcare professionals may nevertheless believe that gatekeeping is justified on the grounds of soft paternalism, based on the belief that survivors might consent to take part in the study, despite the fact that they would not consent to join it were they fully aware of the risks and their own vulnerabilities. For example, they may believe that researchers will downplay potential harms to trauma survivors. ${ }^{70}$ They will also be committed to maintaining the trust this community has placed in them. As a result, since it is typical for people to be cautious in situations of uncertainty, health care professionals may resort to gatekeeping as a protective measure and substitute the judgment of a potential participant with their own. Both hard paternalistic and soft paternalistic justifications of gatekeeping are in some tension with a robust commitment to respect for autonomy-assuming as they do either that individuals will not be able to make choices in line with what they take their interests to be, or that individuals are not entitled to make their own mind up. The latter will be doubly wounding given that this population is already highly marginalised.

However, framing the question for gatekeepers as one of respect for autonomy versus paternalism is at a deeper level somewhat misleading, as it overlooks the fluidity of vulnerability. Members of a marginalised population like sexually tortured refugees may be highly independent and autonomous in some contexts, but vulnerable in others. If so, the appropriate response to such contextual vulnerability is not paternalism, but an awareness of context and the facilitation of a supportive environment. In the final section we examine how a relational ethics, which views the self as relational and contextual rather than autonomous and fixed, and which focuses on needs, care and responsibility ${ }^{71}$ could allow healthcare professionals to respond more usefully to issues associated with this subset of research participants.

\section{A Case for Relational Ethics}

Relationalism and the acceptance of inequality and dependency in human relationships are central to the Ethics of Justice and Care, first coined by Carol Gilligan in $1982 .{ }^{72}$ Its three central tenets are: 1) individuals are social and relational, 2) autonomy is a 'social capacity' and 3) there are particular socio-political conditions necessary to exercise autonomy. ${ }^{73}$ Autonomy is seen as closely linked to social justice because an individual's welfare is increased or diminished depending on supportive or obstructive socio-political conditions. The conceptualisation of care is that of a 'moral practice' rather than a principle, and justice goes further than the mere focus on individual identity and autonomy; it also encompasses responsibility and the equalising of power imbalances. ${ }^{74}$

\footnotetext{
$70 \quad$ Jaffe, A. E., DiLillo, D., Hoffman, op. cit. note 51

71 Loue, S. (2000). Textbook of research ethics. Theory and Practice. New York: Springer

72 Gilligan, C. (1982). In a different voice: psychological theory and women's development. Cambridge:

Harvard University Press

73 Mackenzie, McDowell, \& Pittaway, op. cit. note 31

74 Tronto, J.C. (1993). Moral Boundaries. A Political Argument for an Ethics of Care. New York, London: Routledge
} 
Relationalism does not ignore the otherness of the 'other' nor the positioning of the individual in terms of culture, gender, socio-economic variables and power. Having briefly sketched the fundamentals of relational ethics firmly in place, let us apply these principles to the particular issue of gatekeeping by healthcare professionals in connection with torture survivors.

It could be argued that traumatised refugees require additional — and sometimes differentmeasures due to inequalities in liberties and opportunities. Gatekeeping is then justified as a special procedure to account for those particular vulnerabilities. Yet, while healthcare professionals act as gatekeepers with the intention of protecting their patients where the research codes of bioethics are not robust enough, they are still operating within a paternalistic framework, which inadvertently can cause further marginalization of an already disadvantaged group. Indeed, the challenge that gatekeepers of tortured refugees face is a difficult one: how to adequately respond to their vulnerabilities without being overly paternalistic - how to be protective and diligent without becoming stifling and oppressive, which is likely to reinforce the status quo of silence and domination.

The common goal of all stakeholders is to support survivors without taking away their rights to make choices on their own behalf. Crucial to doing so is moving the notion of respect for autonomy away from an abstract idea and towards a situated one that takes account of power and intersectional disadvantage. This contextualization, which is missing in Principlism, allows us to sufficiently acknowledge the vulnerability and inequality of human research subjects by turning 'the tide of moral discussion' from 'objectivity and detachment' ${ }^{75}$ to a relational ethics of justice and care. In what follows, we will outline the concrete response that arise by adopting this alternative perspective in research concerning tortured refugees. Mackenzie et $\mathrm{al}^{76}$ rightly point out that autonomy is contextual and its exercise hinges on the provision of rights in form of 'social, political and economic protections' ${ }^{77}$ It is the limitation of these rights in the case of displaced and traumatised individuals that infringes on their capacity to exercise autonomy. People are vulnerable not according to a specific definition of vulnerability, but they are vulnerable as it relates to a certain set of socioeconomic circumstances. For instance, the command of a language, a robust social support system, employment and financial power as well as the time elapsed since trauma can modulate vulnerabilities. ${ }^{78,7980}$ There is neither one reality nor one identity-both are multidimensional and intersectional, ${ }^{81}$ and vulnerabilities occur at these intersections (like trauma,

75 Gilligan, C. (1982). In a different voice: psychological theory and women's development. Cambridge: Harvard University Press.

76 Mackenzie, McDowell, \& Pittaway, op. cit. note 31

77 Ibid: 302

78 Bogic, M., Njoku, A., \& Priebe, S. (2015). Long-term mental health of war-refugees: a systematic literature review. BMC International Health and Human Rights. 15(1).

79 Kim, I. (2015). Beyond Trauma: Post-resettlement Factors and Mental Health Outcomes Among Latino and Asian Refugees in the United States. Journal of Immigrant and Minority Health 18(4), pp. 740-748.

80 Young, M.Y., \& Chan K. J. (2015). The psychological experience of refugees: A gender and cultural analysis. In: S. Safdar \& N. Kosakowska-Berezecka (Eds.), Psychology of gender through the lens of culture: Theories and applications. Cham, Switzerland: Springer International Publishing, pp. 17-36.

81 Crenshaw, K. (1991). Mapping the Margins: Intersectionality, Identity Politics, and Violence against Women of Color. Stanford Law Review 43(6). 
migration, race and so on). It also is important that healthcare professionals bear in mind the power imbalance between patients and doctors as to not attribute realities arising from this context to patient's characteristics themselves. ${ }^{82}$ For instance, a torture survivor may seem silent and unwilling to speak in one context but articulate and opinionated in another. Similarly, the mere fact that 'care' is needed indicates a power imbalance - the interaction between the healthcare provider and the tortured refugee is not based on a relationship between equals. We cannot assume that we truly know the position of the 'other', even when our best intentions suggest otherwise. Hence, it is vital that the care provider be honest, self-reflexive and able to regularly re-assess the process of caring. Equally important, the parameters of care must not be viewed as fixed and rigid but instead temporal and fluid. Ephemeral vulnerability does not necessarily translate into a permanent loss of autonomy across all aspects of life. ${ }^{83}$ For example, psychopathology is one reason for gatekeeping by HCPs, yet there is evidence that mental health of tortured refugees depends on a myriad of other pre- and post-migratory factors, which may render some more resilient than others over time. ${ }^{84}$ Furthermore, studies involving minorities have the potential for wide cultural and political implications, and if ignored, this failure to investigate can compound their vulnerabilities. Robert E. Goodin ${ }^{85}$ rightly points out that 'research vulnerability' is not solely determined by particular characteristics of the participant but also the dynamic of the investigation where the well-being of a human subject depends on the conduct of the researcher. Ethical frameworks that emphasise the detachment of a scientist overlook their moral obligations to human research subjects. In truth, the cultural and social aspects of reality can never be fully eliminated to create neutral, value-free and apolitical research. When research with minorities does not take into account their histories of oppression and power imbalances, it runs the risk of replicating those very dynamics. ${ }^{86}$ In this sense, the investigator has a duty to lessen those vulnerabilities. Therefore, it is the moral duty of the researcher to first not diminish the participant's capacity for autonomy and second, to even enhance that capacity. ${ }^{87,88}$

In fact, the caring relationship also places the responsibility on healthcare providers to support the need of traumatised refugees to regain power and autonomy. It is becoming increasingly evident that torture involves a re-making of meaning and re-examining of beliefs and values in one's life. ${ }^{89}$ Hence, gatekeeping runs the risk of suppressing the political agency of torture survivors who may be keen to seize a research opportunity in order to speak out about their demise and advocate for their peers. As feminist and social work theorists argue, justice calls for research to

82 Witham, Beddow, \& Haigh, op. cit. note 69, p. 35

83 Ibid: 146

84 Young, \& Chan, op. cit. note 80

85 Goodin, E. (1985). Protecting the Vulnerable: A Reanalysis of our Social responsibilities. Chicago: University of Chicago Press

86 Fisher, op, cit. note 29, p.13

87 Hugman, Pittaway, \& Bartolomei, op. cit. note 58

88 Tronto, op. cit. note 80

89 Bracken, P. (2001). Post-modernity and post-traumatic stress disorder. Social Science \& Medicine 53(6),pp. 733-743 
take structural oppressions and discriminations into consideration. ${ }^{90,91}$ Such considerations may help to counteract the helplessness and powerlessness that is generated by torture.

By extension, a framework that regards individuals as relational, autonomy as a 'social capacity' and enhancing agency as the purpose of care requires HCPs engage with researchers and deliberate on ethical conflicts. This duty bears upon them because of other dimensions of the power imbalance that inform the normative notions of 'good' and 'harm', consent and information, and purpose and benefit, all of which are grounded in Eurocentric, liberal and individualistic perceptions which do not necessarily carry the same weight cross-culturally and cross-ethnically. ${ }^{92}$ A torture survivor's understanding of what is in their best interest and what constitutes harm may vary depending on ethno-cultural and socioeconomic variables.

Unless we integrate the voices of traumatised refugees at all stages of care as well as research, we are imposing 'foreign' norms on them, contributing to their marginalisation and perpetuating the cycle of Knowledge production that is neither beneficial nor relevant to them. ${ }^{93}$ Such engagement is vitally important as it relates to the most sensitive topics, such as sexual violence, because what we regard sensitive is also shaped by socio-cultural and political factors.

There is no denying that an ethical approach of 'practice' rather than principlism might be challenging to implement, for two main reasons: first, it fails to offer fixed and transparent recommendations for researchers and clinicians to follow; second, it overlooks the stress that is put on an already overstretched and challenged workforce, namely healthcare professionals working with vulnerable groups. However, we would argue that the relational ethics of justice and care is offering a conceptual framework for an activity that has been at the core of modern medicine for many years and is increasingly becoming recognised as a gold standard of academia too, the practice of patient and participation involvement. ${ }^{94}$ Depending on the organisation and patients, this can take place in various forms, from research ethics advisory groups comprising a culturally diverse group of patients to developing ethical guidelines in collaboration with patients to participatory research where communities are involved in research design and planning from the very outset of a project.

\section{Conclusion}

This essay critically evaluated the ethical questions surrounding healthcare professionals' control of access to sexually tortured refugees for the purpose of research recruitment. In summary, the duty of healthcare professionals to minority populations brings upon them serious responsibilities that are not sufficiently captured in the four principles approach to bioethics. The framework of

90 Butler, I. (2000). Critical Commentary: A Code of Ethics for Social Work and Social Care Research. British Journal of Social Work 30,pp. 239-248

91 Dominelli, \& Holloway, op. cit. note 28

92 Rogers, \& Kelly, op. cit. note 39

93 Pittaway, Hugman, \& Bartolomei, op. cit. note 59

94 Wicks, P., Richards, T., Denegri, S. \& Godlee, F. (2018). Patients' roles and rights in research.

BMJ. 
relational ethics of justice and care, on the other hand, meets this duty for three reasons: first, it emphasises the contextual and temporal aspect of vulnerability; second, it adopts a reflexive and accountable approach to the relationship between the care provider and the care receiver; third, it makes provisions to remedy various power imbalances. ${ }^{95}$ It also accounts for the fact that vulnerability and autonomy exist across a spectrum and are not binaries. While this nuanced approach does not give us an easy ethical framework, it does advance justice within the complex reality of traumatised refugees as research participants. Since research with tortured refugee populations is indispensable, an ethical framework of care and justice demands that gatekeepers promote this group's welfare by respecting their agency and levelling the victim-professional power relationships. To achieve this and meet their ethical duties and care responsibilities, it is required that health care professionals honor the triad of stakeholders: traumatised refugees, healthcare providers, and researchers.

In summary, health care professionals' gatekeeping of sexually tortured refugees can be at times necessary and at other times harmful. Elucidating when and how gatekeeping is necessary can be done much more perspicuously through a relational perspective than a four principles approach. The relational perspective places a critical duty on healthcare professionals and gatekeepers to seriously engage research concerning torture survivors and other potentially vulnerable minority populations. Their duty must serve to both care for the potential research participant and help align the power imbalance that they suffer. This, in fact, is an extension of healthcare professionals' duty of care and justice. 